\title{
PENGARUH KOMPENSASI DAN PENGEMBANGAN KARIR TERHADAP KINERJA KARYAWAN
}

\author{
Pramono Margono \\ STIE Unisadhuguna Jakarta, Indonesia \\ Email:pmargono@yahoo.com
}

\begin{abstract}
Abstrak
Pendahuluan : Di era globalisasi, kesiapan sumber daya manusia adalah suatu keharusan. Karena orang adalah aset perusahaan. Tujuan perusahaan bergantung pada kompetensi masyarakat dan disebut kesiapan sumber daya manusia. Karena peningkatan produktivitas karyawan adalah jalan penting untuk meningkatkan kinerja perusahaan.

Tujuan : Tujuan dari penelitian ini adalah untuk memeriksa pengaruh kompensasi dan pengembangan karir pada kinerja karyawan.

Metode : Hipotesis pertama memeriksa kompensasi wheter mempengaruhi kinerja. Hipotesis kedua yang meneliti perkembangan karir wheter mempengaruhi kinerja, Populasi dalam penelitian ini adalah semua karyawan di Perusahaan X Jakarta. Penelitian ini menggunakan dengan menggunakan teknik sampling. Data dikumpulkan menggunakan metode survei dan dianalisis dengan regresi linier dua kali lipat. Hasil tes hipotesis menunjukkan bahwa kompensasi memiliki kinerja yang simultan dan sebagian. Hasil lain dari penelitian ini menunjukkan bahwa pengembangan karir memiliki simultaneon dan sebagian untuk kinerja.

Hasil : Pemberian kompensasi adalah hak para karyawan dan merupakan kewajiban dari pihak perusahaan.

Kesimpulan : Kesimpulan dari penelitian mengenai Pengaruh Kompensasi dan Pengembangan Karir Terhadap Kinerja Karyawan pada studi kasus di PT. X adalah penelitian membuktikan kebenaran dugaan (hipotesis) bahwa terdapat pengaruh parsial dari kompensasi terhadap kinerja karyawan.
\end{abstract}

Kata kunci : Kompensasi; Pengembangan Karir; dan Kinerja Karyawan

\section{Abstract}

Introduction: In the era of globalization, the readiness of human resources is a must. Because people are company assets. The company's goals depend on the competence of the community and are called human resource readiness. Because increasing employee productivity is an important way to improve a company's performance.

Objective: The purpose of this study is to examine the effect of compensation and career development on employee performance.

Method: The first hypothesis of examining wheter compensation affects performance. The second hypothesis that examines wheter career development affects performance, The population in this study is all employees at Company $X$ Jakarta. This study was used using sampling techniques. The data was collected using survey methods and analyzed with two-fold linear regression. Hypothesis test results show that compensation has simultaneous and partial performance. Other results from this study suggest that career development has simultaneon and partly for performance. 
Result: Compensation is the right of employees and is an obligation on the part of the company.

Conclusion: Conclusions from research on the Effect of Compensation and Career Development on Employee Performance on case studies at PT. X is a study proving the truth of the conjecture (hypothesis) that there is a partial effect of compensation on employee performance.

Keywords: Compensation; Career Development; and Employee Performance

\section{Pendahuluan}

Dalam era persaingan bisnis global saat ini dituntut untuk menciptakan kinerja karyawan yang tinggi untuk pengembangan perusahaan. Perusahaan harus mampu membangun dan meningkatkan kinerja di dalam lingkungannya (Ma'ruf Abdullah, 2014). Sumber daya manusia merupakan pelaku dari keseluruhan proses kegiatan produksi mulai dari tingkat perencanaan sampai dengan evaluasi. Dalam menghadapi era globalisasi ini, organisasi termasuk perusahaan perlu meningkatkan kinerjanya agar mampu bersaing dalam banyak konteks (Titisari, 2014). Kapasitas untuk 'berubah' dari sebuah organisasi penting sekali. Organisasi yang harus berubah adalah organisasi yang menggabungkan pembelajaran dalam tempat kerjanya (Darim, 2020), upayanya berupa kualitas adaptasi dan aspek fundamental dimana individu harus melihat kedalam perubahan suatu paradigma. Dalam kontek ini individu haruslah merubah sikap atau dengan kata lain menyesuaikan perkembangan jaman karena individu dianggap sebagai penentu maju mundurnya suatu organisasi (Wijaya, 2017). Dikarenakan individu adalah segalanya bagi perkemban sebuah perusahaan, bahkan bisa dikata bahwa organisasi tanpa individu adalah suatu kebohongan belaka atau tak mungkin (Husaini Abdullah, 2017). Dari hal ini maka kita lihat mengenai sebagian sifat dan pemikiran individu yang harus dimiliki demi tterciptanya sebuah perusahaan yang baik.

Berdasarkan (Mamulati, Triyuwono, \& Mulawarman, 2016) tercapainya tujuan perusahaan tidak hanya tergantung pada peralatan modern, sarana dan prasarana yang lengkap, tetapi justru pada unsur manusianya, karena mereka yang melaksanakan pekerjaan tersebut. Keberhasilan suatu orgnisasi maupun perusahaan akan selalu berusaha untuk meningkatkan kinerja individu karyawannya (Darma, 2020). Setiap organisasi maupun perusahaan akan selalu berusaha untuk meningkatkan kinerja karyawannya, dengan harapan apa yang menjadi tujuan perusahaan akan tercapai.

Sumber daya manusia merupakan pelaku dari keseluruhan proses kegiatan produksi mulai dari tingkat perencanaan sampai dengan evaluasi (Nurjaman, 2014).

Dalam meningkatkan kompetensi serta kinerja karyawannya perusahaan menempuh beberapa cara misalnya melalui pendidikan, pelatihan, pemberian kompensasi yang layak, menciptakan lingkungan kerja yang kondusif, pemberian motivasi dan pengembangan karir. Pemberian kompensasi adalah hak para karyawan dan merupakan kewajiban dari pihak perusahaan. 


\section{Metode Penelitian}

Teknik pengumpulan data menggunakan data primer dan data sekunder yang mana data primer yang digunakan untuk penelitian ini menggunakan instrumen Kuesioner (Unaradjan, 2019). Dan data sekunder yang digunakan adalah data untuk profil dan juga sejarah perusahaan. Kuesioner adalah daftar pertanyaan tertulis yang telah disusun sebelumnya (Choizes, 2017). Pertanyaan-pertanyaan yang terdapat dalam kuesioner, atau daftar pertanyaan tersebut cukup terperinci dan lengkap dan biasanya sudah menyediakan pilihan jawaban (kuesioner tertutup) atau memberikan kesempatan responden menjawab secara bebas (kuesioner terbuka). Dari data yang telah diperoleh ditabulasi dan di analisis menggunakan bantuan Ilmu Statistika dan Program SPSS 22 (Ghozali, 2013).

\section{Hasil dan Pembahasan}

\section{a. Regresi Linear Berganda}

Analisis linear berganda adalah untuk mengetahui pengaruh (naik turunnya) variabel dependent, dari dua atau lebih variabel independent (Kurniawan, 2016). Di sini model tersebut untuk mengetahui seberapa besar pengaruh Kompensasi dan Pengembangan Karir terhadap Kinerja Karyawan.

\section{Tabel 1 Regresi Linear Berganda}

Coefficients $^{\mathrm{a}}$

\begin{tabular}{|c|c|c|c|c|c|c|}
\hline \multirow{2}{*}{\multicolumn{2}{|c|}{ Model }} & \multicolumn{2}{|c|}{$\begin{array}{l}\text { Unstandardized } \\
\text { Coefficients }\end{array}$} & \multirow{2}{*}{$\begin{array}{c}\text { Standardized } \\
\text { Coefficients } \\
\text { Beta }\end{array}$} & \multirow[b]{2}{*}{$\mathrm{t}$} & \multirow[b]{2}{*}{ Sig. } \\
\hline & & $\mathrm{B}$ & Std. Error & & & \\
\hline \multirow[t]{3}{*}{1} & (Constant) & -8.892 & 3.968 & & -2.241 & .027 \\
\hline & $\mathrm{X} 1$ & .466 & .077 & .418 & 6.043 & .000 \\
\hline & $\mathrm{X} 2$ & .476 & .064 & .514 & 7.427 & .000 \\
\hline
\end{tabular}

a. Dependent Variable: Y

Sumber: Hasil Olahan Data (SPSS 22)

Untuk menentukan nilai persamaan regresi linear bergandanya : $\mathrm{Y}^{\prime}=-8.892$ + 0.466 X1 + 0.476 X2, dapat dijelaskan sebagai berikut:

1. Nilai konstanta intersep sebesar -8.892 artinya jika variabel Kompensasi (X1), variabel Pengembangan Karir (X2) tetap (tidak mengalami perubahan) maka nilai variabel Kinerja Karyawan (Y) akan menurun sebesar -8.892

2. Nilai koefisien regresi variabel Kompensasi (X1) terhadap variabel Kinerja Karyawan (Y) adalah 0.466, artinya jika variabel Kompensasi (X1) naik 1 satuan akan meningkatkan variabel Kinerja Karyawan (Y) sebesar 0.466, dengan asumsi variabel Pengembangan Karir (X2) dan konstanta dianggap konstan.

3. Nilai koefisien regresi variabel Pengembangan Karir (X2) terhadap variabel Kinerja Karyawan (Y) sebesar 0.476, berarti jika variabel Pengembangan Karir (X2) naik 1 satuan akan meningkatkan variabel kinerja karyawan (Y) sebesar 0.476, dengan asumsi variabel Kompensasi (X1) dianggap konstan. 


\section{b. Ujit}

1) Hubungan Variabel Kualitas Informasi $\left(\mathrm{X}_{1}\right)$ dengan Kinerja Karyawan (Y)

Hasil tabel coefficients, nilai $t_{\text {hitung }}$ untuk variabel $\mathrm{X}_{1}$ (kompensasi) sebesar 6.043, sedangkan nilai $t_{\text {tabel }}$ untuk $n=100$ sebesar 1.983. Jadi $6.043>1.983$, dapat disimpulkan bahwa secara parsial variabel Kompensasi $\left(\mathrm{X}_{1}\right)$ berkorelasi terhadap Kinerja Karyawan (Y).

2) Hubungan Variabel Sistem Informasi Manajemen $\left(X_{2}\right)$ dengan Kinerja Karyawan (Y)

Jika diperhatikan hasil tabel coefficients di atas dengan menggunakan perhitungan analisis SPSS Versi 16.00 , maka nilai $t_{\text {hitung }}$ untuk variabel $\mathrm{X}_{2}$ (Pengembangan Karir) sebesar 7.427, sedangkan nilai $t_{\text {tabel }}$ untuk $\mathrm{n}=100$ sebesar 1.983. Jadi $7.427>1.983$, dapat disimpulkan bahwa secara parsial variabel Pengembangan Karir $\left(\mathrm{X}_{2}\right)$ berkorelasi terhadap Kinerja Karyawan $(\mathrm{Y})$.

\section{c. Uni Anova $(F)$}

Tabel 2 Koefisien Determinasi Model Summary

\begin{tabular}{lrrrr}
\hline Model & R & R Square & $\begin{array}{c}\text { Adjusted R } \\
\text { Square }\end{array}$ & $\begin{array}{c}\text { Std. Error of the } \\
\text { Estimate }\end{array}$ \\
\hline 1 & $.778^{\mathrm{a}}$ & .605 & .597 & 3.79091 \\
\hline
\end{tabular}

a. Predictors: (Constant), X2, X1

Sumber: Hasil Olahan Data (SPSS 22)

Berdasarkan pada tabel tersebut di atas yakni Model Summary yang menghasilkan nilai $\mathrm{R}$ Square sebesar 0.605, artinya bahwa kompensasi dan pengembangan karir secara bersama-sama mapu menjelaskan variabel kinerja karyawan sebesar $60.5 \%$ sedangkan sisanya sebesar $39.5 \%$ adalah faktor-faktor lain yang tidak diteliti dalam penelitian ini.

d. Model Summary

Tabel 3 Koefisien Determinasi Model Summary

\begin{tabular}{lrrrr}
\hline Model & R & R Square & Adjusted R Square & $\begin{array}{c}\text { Std. Error of the } \\
\text { Estimate }\end{array}$ \\
\hline 1 & $.778^{\mathrm{a}}$ & .605 & .597 & 3.79091 \\
\hline
\end{tabular}

a. Predictors: (Constant), X2, X1

Sumber: Hasil Olahan Data (SPSS 22)

Model Summary yang menghasilkan nilai R Square sebesar 0.605, artinya bahwa kompensasi dan pengembangan karir secara bersama-sama mapu menjelaskan variabel kinerja karyawan sebesar $60.5 \%$ sedangkan sisanya sebesar $39.5 \%$ adalah faktor-faktor lain yang tidak diteliti dalam penelitian ini. 


\section{e. Uji Normalitas}

Uji normalitas pada model regresi digunakan untuk menguji apakah nilai residual yang dihasilkan dari regresi terdistribusi secara normal atau tidak (Nasrum, 2018). Model regresi yang baik adalah yang memiliki nilai residual yang terdistribusi secara normal.

Tabel 4 Hasil Uji Normalitas Data One-Sample Kolmogorov-Smirnov Test

\begin{tabular}{|c|c|c|c|c|}
\hline & & \multicolumn{3}{|c|}{ Standardized Residual } \\
\hline$\overline{\mathrm{N}}$ & & & & 100 \\
\hline \multirow{2}{*}{ Normal Parameters ${ }^{\mathrm{a}, \mathrm{b}}$} & Mean & & & .0000000 \\
\hline & Std. Deviation & & & 98984745 \\
\hline \multirow[t]{3}{*}{ Most Extreme Differences } & Absolute & & & .080 \\
\hline & & Positive & | & .080 \\
\hline & & & Negative & -.046 \\
\hline Test Statistic & & & & .080 \\
\hline Asymp. Sig. (2-tailed) & & & & $.121^{\mathrm{c}}$ \\
\hline
\end{tabular}

a. Test distribution is Normal.

b. Calculated from data.

c. Lilliefors Significance Correction.

\section{f. Uji Multikolinearitas}

Sumber: Hasil Olahan Data (SPSS 22)

Uji multikolinearitas dilakukan dengan menghitung nilai variance inflation factor (VIF) tiap -tiap variabel independent (Widhiarso \& UGM, 2012). Multikolinearitas terjadi jika nilai Variance Inflation Factor (VIF) melebihi 10. Jika nilai Variance Inflation Factor (VIF) kurang dari 10 menunjukkan bahwa korelasi antar variabel independen masih bisa ditolerir.

Tabel 5 Hasil Uji Multikolinearitas Coefficients $^{\mathrm{a}}$

\begin{tabular}{|c|c|c|c|c|c|c|c|}
\hline \multirow[b]{2}{*}{ Model } & \multicolumn{2}{|c|}{$\begin{array}{c}\text { Unstandardized } \\
\text { Coefficients }\end{array}$} & \multirow{2}{*}{\begin{tabular}{|c}
$\begin{array}{c}\text { Standardized } \\
\text { Coefficients }\end{array}$ \\
Beta
\end{tabular}} & \multirow[b]{2}{*}{$\mathrm{t}$} & \multirow[b]{2}{*}{ Sig. } & \multicolumn{2}{|c|}{$\begin{array}{c}\text { Collinearity } \\
\text { Statistics }\end{array}$} \\
\hline & B & $\begin{array}{l}\text { Std. } \\
\text { Error }\end{array}$ & & & & Tolerance & VIF \\
\hline 1 (Constant) & -8.892 & 3.968 & & 2.241 & .027 & & \\
\hline $\mathrm{X} 1$ & .466 & .077 & .418 & 6.043 & .000 & .851 & 1.176 \\
\hline $\mathrm{X} 2$ & .476 & .064 & .514 & 7.427 & .000 & .851 & 1.176 \\
\hline
\end{tabular}

a. Dependent Variable: Y

$$
\text { Sumber: Hasil Olahan Data (SPSS 22) }
$$

Berdasarkan tabel di atas, dapat diketahui bahwa nilai Variance Inflation Factor (VIF) dari masing-masing variabel independent tidak memiliki nilai yang lebih dari 10, sehingga dapat disimpulkan bahwa model regresi dalam penelitian ini tidak mengandung multikolinieritas. 


\section{g. Uji Heteroskedastisitas}

Uji heteroskedastisitas bertujuan untuk menguji apakah dalam model regresi terjadi ketidaksamaan varians dari residual satu pengamatan ke pengamatan yang lain (Khoiroh, 2011). Model regresi yang baik adalah tidak terjadi gejala heteroskedastisitas.

\section{Hasil Uji Heteroskedastisitas}

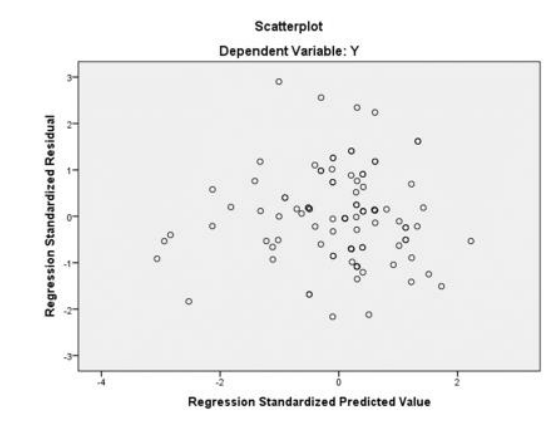

Sumber: Hasil Olahan Data (SPSS 22)

Berdasarkan gambar di atas dapat diketahui bahwa titik-titik tidak membentuk pola yang jelas, dan titik-titik menyebar di atas dan di bawah angka 0 pada sumbu Y. Jadi dapat disimpulkan bahwa tidak terjadi gejala heteroskedastisitas dalam model regresi.

\section{Kesimpulan}

Kesimpulan dari penelitian mengenai Pengaruh Kompensasi dan Pengembangan Karir Terhadap Kinerja Karyawan pada studi kasus di PT. X adalah penelitian membuktikan kebenaran dugaan (hipotesis) bahwa terdapat pengaruh parsial dari kompensasi terhadap kinerja karyawan. Hal tersebut dapat dilihat dari $t_{\text {hitung }}$ untuk variabel $\mathrm{X}_{1}$ (kompensasi) sebesar 6.043, sedangkan nilai $\mathrm{t}_{\text {tabel }}$ untuk $\mathrm{n}=100$ sebesar 1.983. Jadi $6.043>1.983$, dapat disimpulkan bahwa secara parsial variabel kompensasi $\left(\mathrm{X}_{1}\right)$ berkorelasi positif signifikan terhadap kinerja karyawan $(\mathrm{Y})$ pada $\alpha=5 \%$. Penelitian membuktikan kebenaran dugaan (hipotesis) bahwa terdapat pengaruh parsial dari Pengembangan Karir terhadap kinerja karyawan Hal ini dapat dilihat dari nilai $t_{\text {hitung }}$ untuk variabel $\mathrm{X}_{2}$ (pengembangan karir) sebesar 7.427, sedangkan nilai $\mathrm{t}_{\text {tabel }}$ untuk $\mathrm{n}=$ 100 sebesar 1.983. Jadi $7.427>1.983$, dapat disimpulkan bahwa secara parsial variabel pengembangan karir $\left(\mathrm{X}_{2}\right)$ berkorelasi positif signifikan terhadap kinerja karyawan $(\mathrm{Y})$ pada $\alpha=5 \%$. Penelitian membuktikan kebenaran dugaan (hipotesis) bahwa terdapat pengaruh simultan dari Kompensasi dan Pengembangan Karir terhadap Kinerja Karyawan. Hal tersebut dapat kita lihat dari nilai $F_{\text {hitung }}$ sebesar 74.296, sedangkan nilai $\mathrm{F}_{\text {tabel }}$ untuk $\mathrm{n}=100$ sebesar 3.09. Jadi $74.296>3.09$, dapat disimpulkan bahwa kualitas informasi dan sistem informasi manajemen secara bersama-sama/simultan berkorelasi dengan kinerja karyawan (Y) pada $\alpha=5 \%$. 


\section{DAFTAR PUSTAKA}

Abdullah, Husaini. (2017). Peranan manajemen sumberdaya manusia dalam organisasi. Warta Dharmawangsa, (51).

Abdullah, Ma'ruf. (2014). Manajemen dan evaluasi kinerja karyawan. Aswaja Pressindo.

Choizes, E. (2017). Pengertian Skala Likert dan Contoh Cara Hitung Kuesionernya. Online] Tersedia di:< https://www. diedit. com/skala-likert/>[Diakses 12 ...

Darim, Abu. (2020). Manajemen Perilaku Organisasi Dalam Mewujudkan Sumber Daya Manusia Yang Kompeten. Munaddhomah: Jurnal Manajemen Pendidikan Islam, 1(1), 22-40.

Darma, Satria. (2020). Eksistensi Akuntansi Sumber Daya Manusia Sebagai Aset. JAS (Jurnal Akuntansi Syariah), 4(1), 1-15.

Ghozali, Imam. (2013). Aplikasi Analisis Multivariente Dengan Program SPSS 21. Semarang: Badan Penerbit Universitas Diponegoro, 100, 125.

Khoiroh, Umdatul. (2011). Uji Heteroskedastisitas pada Regresi Nonparametrik. UNIVERSITAS AIRLANGGA.

Kurniawan, Robert. (2016). Analisis regresi. Prenada Media.

Mamulati, Irman, Triyuwono, Iwan, \& Mulawarman, Aji Dedi. (2016). Fenomenologi sumber daya manusia sebagai aset intelektual dalam amal usaha Muhammadiyah. Journal of Accounting and Investment, 17(1), 93-103.

Nasrum, Akbar. (2018). Uji normalitas data untuk penelitian. Jayapangus Press Books, $\mathrm{i}-117$.

Nurjaman, Kadar. (2014). Manajemen Personalia.

Titisari, Purnamie. (2014). Peranan organizational citizenship behavior (OCB) dalam meningkatkan kinerja karyawan.

Unaradjan, Dominikus Dolet. (2019). Metode penelitian kuantitatif. Penerbit Unika Atma Jaya Jakarta.

Widhiarso, Wahyu, \& UGM, Fakultas Psikologi. (2012). Tanya jawab tentang uji normalitas. Fakultas Psikologi UGM (Diakses Pada 7 Desember 2016).

Wijaya, Candra. (2017). Perilaku organisasi. 